\title{
Why does Mycophenolate use only for kidney complications in Schonlein Henoch Syndrome? Case report
}

Maria Francesca Gicchino ( $\nabla$ francesca.gicchino@gmail.com )

Universita degli Studi della Campania Luigi Vanvitelli https://orcid.org/0000-0003-0329-6583

Dario lafusco

Universita degli Studi della Campania Luigi Vanvitelli

Maria Maddalena Marrapodi

Universita degli Studi della Campania Luigi Vanvitelli

Rosa Melone

Universita degli Studi della Campania Luigi Vanvitelli

Giovanna Cuomo

Universita degli Studi della Campania Luigi Vanvitelli

Angela Zanfardino

Universita degli Studi della Campania Luigi Vanvitelli

Emanuele Miraglia del Giudice

Universita degli Studi della Campania Luigi Vanvitelli

Alma Nunzia Olivieri

Universita degli Studi della Campania Luigi Vanvitelli

\section{Case Report}

Keywords: Shonlein Henoch Syndrome, Purpura, Mycophenolate Mofetile

Posted Date: March 11th, 2020

DOI: https://doi.org/10.21203/rs.3.rs-16795/v1

License: (c) (i) This work is licensed under a Creative Commons Attribution 4.0 International License.

Read Full License 


\section{TITLE PAGE}

Why does Mycophenolate use only for kidney complications in Schonlein Henoch Syndrome? Case report

Maria Francesca Gicchino, Dario lafusco, Maria Maddalena Marrapodi, Rosa Melone, Giovanna Cuomo*, Angela Zanfardino, Emanuele Miraglia del Giudice, Alma Nunzia Olivieri

Department of Woman, Child and General and Specialized Surgery, Naples, Italy *Department of Precision Medicine, Naples, Italy

University of Campania “Luigi Vanvitelli”, Naples, Italy

Corresponding Author: Maria Francesca Gicchino

Via De Crecchio, 4 - 80138 Naples - Italy

almanunzia.olivieri@unicampania.it

Phone + 390815665428

Mobile + 393398826510

Fax +390815665430

Words count 1,720 
Why does Mycophenolate use only for kidney complications in Schonlein Henoch Syndrome?

Maria Francesca Gicchino, Dario lafusco, Maria Maddalena Marrapodi, Rosa Melone, Giovanna Cuomo*, Angela Zanfardino, Emanuele Miraglia del Giudice, Alma Nunzia Olivieri

\section{Background:}

Henoch Schonlein purpura (HSP) is an acute small vessel vasculitis. It is the most common vasculitis in children. Although the cause is unknown, IgA seems to play a central role in the pathogenesis of Henoch Schonlein purpura. The major clinical features include a palpable purpuric rash on the lower extremities, abdominal pain or renal involvement, and arthritis. Cutaneous manifestations are the essential elements in the diagnosis of Henoch Schonlein purpura. The palpable purpura is characteristically 2 to $10 \mathrm{~mm}$ in diameter and is usually present on the lower extremities. There are no specific diagnostic tests available for diagnosing this condition. Laboratory studies are useful to exclude other conditions that may mimic Henoch Schonlein purpura. In majority of the cases, the disease is self-limited. Relapsing can occur, in particular during the first year of the disease. There is no consensus on a specific treatment. Corticosteroids are effective in rapid resolution of renal and abdominal manifestations. Immunosuppressive drugs, such as Mycophenolate Mofetil may be a better treatment choice in case of renal involvement.

Case report: We report a case of a 14 years old girl affected from recurrent Henoch Schonlein Purpura. From the age of nine years patient presented three episodes of purpura with gastrointestinal involvement, in particular hematemesis, abdominal pain and diarrhoea. Each episode was treated with high doses of corticosteroids (methylprednisolone in vein or prednisone per os). Patient came to our Department during the third episode of Purpura. In consideration of the recurrence of the Henoch Schonlein Purpura and the gastrointestinal involvement we decided to start Mycophenolate Mofetil treatment. Patient's conditions improved thanks to Mycophenolate treatment. Conclusion:.In our case of recurrent HSP Mycophenolate Mofetil treatment has been very effective, avoiding the adverse events of a prolonged steroid treatment. This experience teaches us that immunosuppressive agents may be very useful to induce and maintain remission not only in renal involvement, but in all cases of persistence, recurrence or complicated forms of Henoch Schonlein purpura in children.

\section{Key Words}

Shonlein Henoch Syndrome, Purpura, Mycophenolate Mofetile 


\section{Background}

66 Henoch-Schönlein purpura (HSP) is the most common systemic vasculitis in children ${ }^{1}$. The majority of those patients are under 10 years old ${ }^{2}$. Annual incidence of HSP in children is estimated to be $15 / 100,000$ cases. $^{3}$ The proportion of males and females in children is close to $2: 1 .^{4}$ Diagnostic criteria were published by the European League against Rheumatism and the Pediatric Rheumatology European Society which include palpable purpura (obligatory) in combination with at least one of other manifestations (gastrointestinal involvement, immunoglobulin A deposition in biopsy, arthritis or arthralgia, and renal involvement) ${ }^{5}$ Table1. Clinical manifestations are: palpable purpura (96\%), arthralgia/arthritis (64\%), abdominal pain (66\%), gastrointestinal bleeding (28\%), renal involvement (39\%), subcutaneous edema (42\%), orchitis (5\%). Patient may present rarely severe pulmonary hemorrhage $(1 \%)$, or cerebral vasculitis $(2 \%) .{ }^{6}$ Purpuric rashes are the most typical manifestation. The prognosis of HSP is generally good, but recurrence is common among children (recurrence rate, $2.7 \%-66.2 \%)^{7}$. Significant morbidity and mortality are associated with gastrointestinal tract lesions and nephritis. The development of major indicators of renal disease within the first six months after onset or the recurrence of numerous exacerbations associated with nephropathy suggests a poor prognosis for renal function. Additional poor prognosis factors are decreased factor XIII activity,

81 hypertension, renal failure at onset. ${ }^{8}$ Treatment is supportive, with maintenance of good hydration, and with control of pain with analgesics. However, the efficacy and safety of the therapy with steroids and immunosuppressants in treating HSP are still controversial. ${ }^{10}$ Corticosteroids are useful in children with gastrointestinal disease, hemorrhage, severe orchitis, kidney involvement. Immunosuppressive treatment of HSP nephritis is used in patients with severe kidney involvement (nephrotic range proteinuria and/or progressive renal impairment). ${ }^{11}$ There are few data in literature regarding treatment of recurrent HSP without kidney involvement. We report the successful use of MMF in a patient affected from recurrent HSP with gastrointestinal involvement. 


\begin{tabular}{|l|l|}
\hline Criterion & Definition \\
\hline Purpura ( mandatory) & $\begin{array}{l}\text { Purpura palpable or petechiae, with lower limb } \\
\text { predominance, not related to thrombocytopenia }\end{array}$ \\
\hline At last 1 of the following & $\begin{array}{l}\text { Diffuse, acute coliky pain. May due to } \\
\text { intussusception and gastrointestinal bleeding }\end{array}$ \\
\hline Abdominal pain & $\begin{array}{l}\text { Leucocytoclastic vasculitis with IgA deposit, or } \\
\text { proliferative glomerulonephritis with IgA } \\
\text { deposit }\end{array}$ \\
\hline Histopathology & $\begin{array}{l}\text { Arthritis. Acute joint swelling or pain with } \\
\text { limitation on motion. Arthralgia. Acute joint } \\
\text { pain without joint swelling or limitation on } \\
\text { motion }\end{array}$ \\
\hline Renal involvement & $\begin{array}{l}\text { Proteinuria>0.3g/24hr; spot urine albumin to } \\
\text { creatinine ratio>30mmol/mg, or 2+on dipstick } \\
\text { Hematuria, red cell casts. Urine sediment } \\
\text { showing }>5 \text { red cells per high power field or } \\
\text { red cells casts }\end{array}$ \\
\hline
\end{tabular}

Table n 1 :Modified from Ozen S. et al. The EULAR/PRINTO/PRES criteria for HSP, Ann Rheum Dis $2010^{5}$

\section{Case presentation}

Episode 1 (2012). At the age of 8 years, after a febrile pharyngitis treated with Amoxicillineclavulanic, patient presented pain in her lower limbs with difficulty walking and purpuric lesions to the limbs. During hospitalization in a local hospital she was treated with oral prednisone, $2 \mathrm{mg} / \mathrm{kg} / \mathrm{die}$. She was discharged for disappearance of symptoms after 1 week with diagnosis of suspected vasculitis and therapy with prednisone $(2 \mathrm{mg} / \mathrm{kg} / \mathrm{die})$ for 10 days.

Episode 2 (2015) After three years of good conditions, patient presented hematemesis and purpuric lesions so she was hospitalized again. Laboratory tests: complete blood count, kidney and liver parameters, electrolytes and coagulation test, urinalysis, faecal calprotectin, antinuclear antibodies (ANA) celiac screening, virological testing, throat swab were unremarkable. Abdomen ultrasound, was normal. Methylprednisolone iv $(30 \mathrm{mg} / \mathrm{kg} / \mathrm{die})$ was started, then oral prednisone $(25 \mathrm{mg}$ twice a day) was prescribed. She was discharged after 1 month with Schonlein Henoch Vasculitis diagnosis. 
110 presented relapse with hematemesis and purpuric lesions, so she was hospitalized again. She

111 underwent esophagogastroduodenoscopy (EGDS) that was negative. Resigned with corticosteroids

112 therapy (oral prednisone $25 \mathrm{mg}$ twice a day) for about a month. Patient presented good condition for 113 three years.

114 Episode 3 (March 2018), at the age of 15 years after an episode of pharyngitis appearance of diffuse 115 rash, so she was admitted in hospital again with diagnosis of vasculitis and corticosteroids treatment 116 for 10 days (oral prednisone $25 \mathrm{mg}$ twice a day) was prescribed. As she suspended corticosteroids 117 treatment she presented again purpuric lesions on the lower limbs. So she was admitted to the 118 hospitalized again. During hospitalization oral prednisone $(50 \mathrm{mg} / \mathrm{die})$ was started again. In this 119 occasion patient presented the first episode of hypertension. Laboratory tests (complete blood count, 120 kidney and liver parameters, coagulations tests, ANA, rheumatoid factor, inflammatory indices, 121 immunoglobulins, complement $\mathrm{C} 3$ and $\mathrm{C} 4$, thyroid hormone, urinalysis, virological examinations), 122 throat swab were negative. Skin biopsy was suggestive of leukocytoclastic vasculitis, with IgA 123 deposition, typical of HSP.HSP was confirmed and oral steroids (prednisone $25 \mathrm{mg}$ twice a day, 124 gradually reduced) was prescribed. As she reduced oral prednisone, hematemesis, epistasis and 125 diarrhea came back again. Patient was evaluated to emergency and she underwent to abdomen 126 ultrasonography revealing bowel wall thickening. Steroids were prescribed again by increasing the 127 dosage (prednisone $25 \mathrm{mg}$ twice a day). For the persistence of abdominal pain and maculo papular 128 lesions on the limbs, trunk, abdomen patient came to our observation for the first time. Secondary 129 amenorrhea since four months was referred. On the examination she presented acne on the face and 130 back. No arthritis was detected. Her blood tests were unremarkable for: complete blood count, liver 131 and kidney function, erythrocyte sedimentation rate (ERS), C-reactive protein (CRP), Antinuclear 132 antibodies (ANA), extractable nuclear antigens (ENA), Anti neuthophil Cytoplasmic antibodies 133 (ANCA), rheumatoid factor (RF), anti-double stranded DNA (dsDNA) immunoglobulins, 134 complement C3 and C4, thyroid hormone, sexual hormones, blood cortisol . Factor XIII activity was 135 reduced $(65 \%$, normal value $>75 \%)$. Urinalysis was normal. Throat swab was negative. Abdomen 
and pelvic ultrasound was in the norm. Both gynecological and ophthalmologic evaluation were

137 normal. So therapy with oral prednisone $25 \mathrm{mg}$ in the morning and $20 \mathrm{mg}$ in the evening was 138 prescribed. After few days she presented new purpuric lesions at the knees and feet, so therapy with 139 mycophenolate mofetil (750mg twice a day) was added to oral prednisone $(40 \mathrm{mg} / \mathrm{die})$ due to the 140 recurrent nature of her symptoms and the lack of a sustained response to glucocorticoids. She 141 performed mycophenolate mofetil therapy for 8 months, with complete regression of vasculitic 142 lesions. Patient had sustained remission for 12 months off corticosteroids and MMF. At the last 143 follow up visit patient was in good conditions, she did not present rash or vasculitic lesions and 144 laboratory test was normal.

\section{Discussion}

147 We described a case of a patient affected from recurrent HSP with gastrointestinal involvement who had been successfully treated with MMF .The treatment of HSP is controversial. In clinical practice management of HSP includes supportive care, symptomatic therapy and, in some cases, immunosuppressive treatment. Arthritis/arthralgia usually responds well to non-steroidal anti-

151 inflammatory drugs (NSAIDs). Specific therapy is limited to the care of the most important complications including especially kidney involvement. Steroids have been the first-line therapeutic regimen for many kinds of glomerulo-nephritis over years ${ }^{10}$. Corticosteroids are useful in children with gastrointestinal disease, hemorrhage, severe orchitis, kidney involvement. Early GCS treatment have included shorter duration of abdominal pain, decreased risk of intussusception and decreased risk of surgical intervention. ${ }^{12,13}$. Immunosuppressive treatment of HSP nephritis is used in patients with severe kidney involvement (nephrotic range proteinuria and/or progressive renal impairment) ${ }^{10}$.

158 Recent studies in children with HSP nephritis and nephrotic syndrome suggest a potential benefit of cyclosporine A (CsA) or Mycofenolate Mofetil in achieving remission of proteinuria.$^{14,15}$

160 In our case the patient presented a severe gastrointestinal involvement responsive to high and 161 prolonged doses of corticosteroids with all the side effects that this therapy entailed so we decided to 
start an immunosuppressive treatment with Mycophenolate Mofetil. This drug is very effectiveness

163 in many rheumatological diseases also in paediatric age such as lupus erythematous systemic and

164 vasculitis.$^{16}$ In table 2 are described all the side effects of all immunosuppressant drugs used for

165 treatment of vasculitis. Adverse effects of MMF include diarrhoea, bone marrow suppression,

166 opportunistic infections; these side effects are rare and less severe than the secondary consequence

167 of prolonged corticosteroid therapy. In particular, in children, a long exposure to corticosteroid could

168 induce also growth impairment. MMF seems to be an effective steroid-sparing medications, allowing

169 steroid-dipendent patients to be tapered off steroids. No official guidelines are available for treatment

170 duration.

Table $2^{17}$

176

177

178

179

180

181

182

183

\begin{tabular}{|c|c|c|c|c|c|c|}
\hline & $\begin{array}{l}\text { Cyclophosphamide } \\
\text { (CYC) }\end{array}$ & Azathioprine & $\begin{array}{l}\text { Mycophenolate } \\
\text { mofetil (MMF) }\end{array}$ & Ciclosporin & Methotrexate & Corticosteroids \\
\hline Dose & $\begin{array}{l}2-3 \mathrm{mg} / \mathrm{kg} \text { once a } \\
\text { day PO } 2-3 \\
\text { months; } 0.5- \\
1.0 \mathrm{~g} / \mathrm{m} 2 \mathrm{IV} \\
\text { monthly with } \\
\text { mesna to prevent } \\
\text { cystitis }\end{array}$ & $\begin{array}{l}0.5-2.5 \mathrm{mg} / \mathrm{kg} \\
\text { once a day PO } \\
\text { for } 1 \mathrm{yr} \text { or } \\
\text { more }\end{array}$ & $\begin{array}{l}(600 \mathrm{mg} / \mathrm{m} 2 \\
\text { twice a day })\end{array}$ & $\begin{array}{l}3-5 \mathrm{mg} / \mathrm{kg} / \text { day } \\
\text { PO in } 2 \\
\text { divided doses }\end{array}$ & $\begin{array}{l}10-15 \\
\mathrm{mg} / \mathrm{m} 2 / \text { week } \\
\text { PO or SC } \\
\text { (single dose) }\end{array}$ & $\begin{array}{l}\text { Prednisolone } \\
1-2 \mathrm{mg} / \mathrm{Kg} \text { PO } \\
\text { Prednisone } \\
1-2 \mathrm{mg} / \mathrm{Kg} \text { PO } \\
\text { MetilPrednisolone } \\
30 \mathrm{mg} / \mathrm{kg} \text { max } 1 \mathrm{~g} \\
\text { EV }\end{array}$ \\
\hline $\begin{array}{l}\text { Side } \\
\text { Effects }\end{array}$ & $\begin{array}{l}\text { Leucopenia ; } \\
\text { haemorrhagic } \\
\text { cystitis; leukaemia, } \\
\text { lymphoma, } \\
\text { transitional cell } \\
\text { carcinoma of } \\
\text { bladder }\end{array}$ & $\begin{array}{l}\text { GI toxicity; } \\
\text { hepatotoxicity; } \\
\text { no increase in } \\
\text { malignancy in } \\
\text { adults with } \\
\text { RA; no } \\
\text { conclusive data } \\
\text { for cancer risk } \\
\text { in children }\end{array}$ & $\begin{array}{l}\text { Bone marrow } \\
\text { suppression; } \\
\text { severe } \\
\text { diarrhoae; } \\
\text { pulmonary } \\
\text { fibrosis }\end{array}$ & $\begin{array}{l}\text { Renal } \\
\text { impairment, } \\
\text { hypertension, } \\
\text { hepatotoxicity, } \\
\text { tremor, } \\
\text { gingival } \\
\text { hyperplasia, } \\
\text { hypertricosis, } \\
\text { lymphoma }\end{array}$ & $\begin{array}{l}\text { Bone marrow } \\
\text { suppression } \\
\text { and interstitial } \\
\text { pneumonitis ( } \\
\text { risk with folic } \\
\text { acid), } \\
\text { reversibile } \\
\text { elevation of } \\
\text { transaminases, } \\
\text { hepatic fibrosis }\end{array}$ & $\begin{array}{l}\text { Growth Imparment } \\
\text { Diabetes } \\
\text { Hypertension } \\
\text { Dyselectrolites } \\
\text { Oedema } \\
\text { Hypokaliemia } \\
\text { Osteopenia } \\
\text { Musles atrophy }\end{array}$ \\
\hline
\end{tabular}

Side effects and dose of main drugs used for the chronic treatment of vasculitis

\section{Conclusions}

This anecdotal case demonstrates that MMF may be beneficial for the induction and maintenance of remission of recurrent HSP with gastrointestinal involvement representing steroid sparing medications. Our patient had no adverse events associated with MMF therapy. Immunosuppressant agents should be useful for the induction and maintenance of remission of all persistence, recurrence 
treatments for these patients are needed.

\section{List of abbreviations}

SHP: Shonlein Henoch Purpura

MMF: Mycophenolate Mofetile

ANA: Anti Nuclear Antibodies

ANCA: Anti Neutrophil Cytoplasmic Antibodies

ENA: Extractable Nuclear Antigens

RF: Rheumatoid Factor

DS-DNA: Anti Duble Stranded-DNA

EGDS: Esophagogastroduodenoscopy

ESR: Erythrocyte Sedimentation Rate

CRP: C-Reactive Protein

NSAIDs: non Steroidal Anti Inflammatory Drugs

GCS: Glucocorticosteroids

CSA: Cyclosporine A

Ethical approval: Not applicable

Consent to participate: Not applicable

Consent for publication Written consent for publication has been obtained from the parents of the patient

Availability of data and material: Not applicable

Competing Interests: Authors declare no potential competing interests with respect to research authorship and/or publication of this article

Funding: Not applicable

Authors' contributions: GMFconceived the paper, involvement in the diagnosis and follow up of patient, analyzed and interpreted the patient data and first writer of paper; MMM, MR and ZA diagnosis and management of patient, analyzed and interpreted the patient data, writer of paper and revision of bibliography; ID, CG, MDGE and OAN supervision of the medical procedures, including the decision of the use of MMF, writer of paper.

All authors read and approved the final manuscript.

Acknowledgements

We are grateful to Prof Ranjith Kothalawalage for the English revision of this paper 
${ }^{1}$ Hetland LE, Susrud KS, Lindahl KH, et al. Henoch-Schonlein purpura: a literature review. Acta Derm Venereol 2017; 97: 1160-6.

${ }^{2} \mathrm{He} \mathrm{X}, \mathrm{Yu} \mathrm{C}$, Zhao P, et al The genetics of Henoch-Schonlein purpura: a systematic review and meta-analysis. Rheumatol Int 2013; 33(6): 1387-1395.

${ }^{3}$ Kang Y, Park JS. Differences in clinical manifestations and outcomes between adult and child patients with Henoch-Schonlein purpura. J Korean Med Sci 2014; 29: 198-203.

${ }^{4}$ Reid-Adam J. Henoch-Schonlein purpura. Pediatr Rev 2014; 35: 447-9.

${ }^{5}$ Ozen, S., Pistorio, A., Iusan, S. M. et al. EULAR/PRINTO/PRES criteria for Henoch-Schonlein purpura, childhood polyarteritis nodosa, childhood Wegener granulomatosis and childhood Takayasu arteritis: Ankara 2008. Part II: Final classification criteria. Annals of the Rheumatic Diseases, 2010; 69(5): 798-806.

${ }^{6}$ Cassidy JT, Petty RE, Laxer RM et al. Textbook of pediatric rheumatology Ed Elsevier 2011

${ }^{7}$ Wei-Te L, Po-Li T, Szu-Hung C, et al. Incidence and risk factors for recurrent Henoch-Schönlein purpura in children from a 16-year nationwide database. Pediatr Rheumatol Online J. 2018; 16: 25.

${ }^{8}$ Rao S, Singhal V, Kamath N. Henoch Schonlein Purpura: classification and management- an update. Karnataka Paediatric Journal 2012; 26, No 1

${ }^{9}$ Fotis L, Tuttle PV, Baszis KW, et al Azathioprine therapy for steroid resistant Henoch Schonlein Purpura: A report of 6 cases Pediatric Rheumatology 2016;14:37

${ }^{10}$ Jiaxing T, Yi T, Zhengxia Z, et al The efficacy and safety of immunosuppressive agents plus steroids compared with steroids alone in the treatment of Henoch-Schonlein purpura nephritis: A meta-analysis. Int Urology and Nephrology 2019. Doi 10.1007/s11255-019-02092-7

${ }^{11}$ Hetland E, Kjærsti Sørensen S, Hein Lindahl K and Bygum A Henoch-schonlein purpura: a literature review. Liv Acta Derm Venereal 2017; 97: 1160-1166

12 Fangfang Y, Zhaohui B, Yingying L et al. A good response to glucocorticoid for HenochSchönlein purpura with abdominal pain and gastrointestinal bleeding in an adult A care case report Medicine 2020; 99(1): e18602.

${ }^{13}$ Weiss PF, Klink AJ, Localio R et al. Corticosteroids may improve clinical outcomes during hospitalization for Henoch-Schönlein purpura. Pediatrics 2010; 126: 674- 681.

${ }^{14}$ Park JM, Won SC, Shin JI et al. Cyclosporin A therapy for Henoch-Schönlein nephritis with nephrotic range proteinuria. Pediatr. Nephrol. 2011; 26: 411- 417.

15 Hackl, A., Becker, J. U., Körner, et al. Mycophenolate mofetil following glucocorticoid treatment in Henoch-Schönlein purpura nephritis: the role of early initiation and therapeutic drug monitoring. Pediatric Nephrology, 2017; 33(4), 619-629 
${ }^{16}$ Rodriguez-Smith J, Brunner HI Update on the treatment and outcome of systemic lupus erythematous in children. Curr Opin Rheumatol. 2019; 31(5): 464-470.

${ }^{17}$ Foster H and Brogan P Paediatric Rheumatology -Ed OSH Paediatrics 2012 


\section{Supplementary Files}

This is a list of supplementary files associated with this preprint. Click to download.

- checklist.pdf

- checklist.pdf 